\title{
TRÍADE DE CARNEY
}

\section{CARNEY'S TRIAD}

\section{Maria da Glória Patello de Moraes, TcCBC-RJ ${ }^{1}$ Nelson Medina Coeli, ECBC-RJ ${ }^{2}$ José Geraldo Alves de Menezes ${ }^{3}$}

\section{INTRODUÇÃO}

Em 1983, Carney descreveu uma tríade constituída por leiomiossarcoma gástrico epitelióide, condroma pulmonar e paraganglioma extra-adrenal funcionante. Apresentou 24 casos, dos quais seis tinham a síndrome completa e 18, apenas dois componentes. Em 1999, já com o conceito atual de tumores estromais, encontrou, na literatura mundial, 79 pacientes, sendo que em 62 casos (78\%) a ocorrência foi de apenas dois componentes da tríade.

Nosso objetivo é apresentar mais um caso desta síndrome rara. Ressaltamos que, quando o diagnóstico de um dos componentes da tríade for feito, o paciente deverá ser acompanhado na busca das outras manifestações clínicas que poderão surgir a grandes intervalos de tempo.

\section{RELATO DO CASO}

Mulher de 53 anos, professora, em bom estado geral, apresentou quadro de dor epigástrica e hematêmese. A endoscopia digestiva alta mostrou volumosa lesão polipóide na junção esofagogástrica, associada a múltiplas tumorações de tamanhos variados, revestidas por mucosa íntegra, distribuídas pelo corpo e antro gástrico. Uma das lesões do corpo apresentava ulceração de $0,6 \mathrm{~cm}$ de diâmetro, de bordos nítidos e fundo hemorrágico. A macrobiopsia demonstrou tratar-se de tumor estromal do trato gastrintestinal.

No raios $\mathrm{X}$ de tórax, solicitado na rotina pré-operatória, e confirmado na tomografia computadorizada, verificou-se a presença de grande massa em pulmão direito, medindo cerca de $8 \mathrm{~cm}$ de diâmetro e outras lesões menores, com as mesmas características, distribuídas aleatoriamente por ambos os pulmões (Figura 1).Tais lesões, diagnosticadas como condromatose pulmonar, em nada
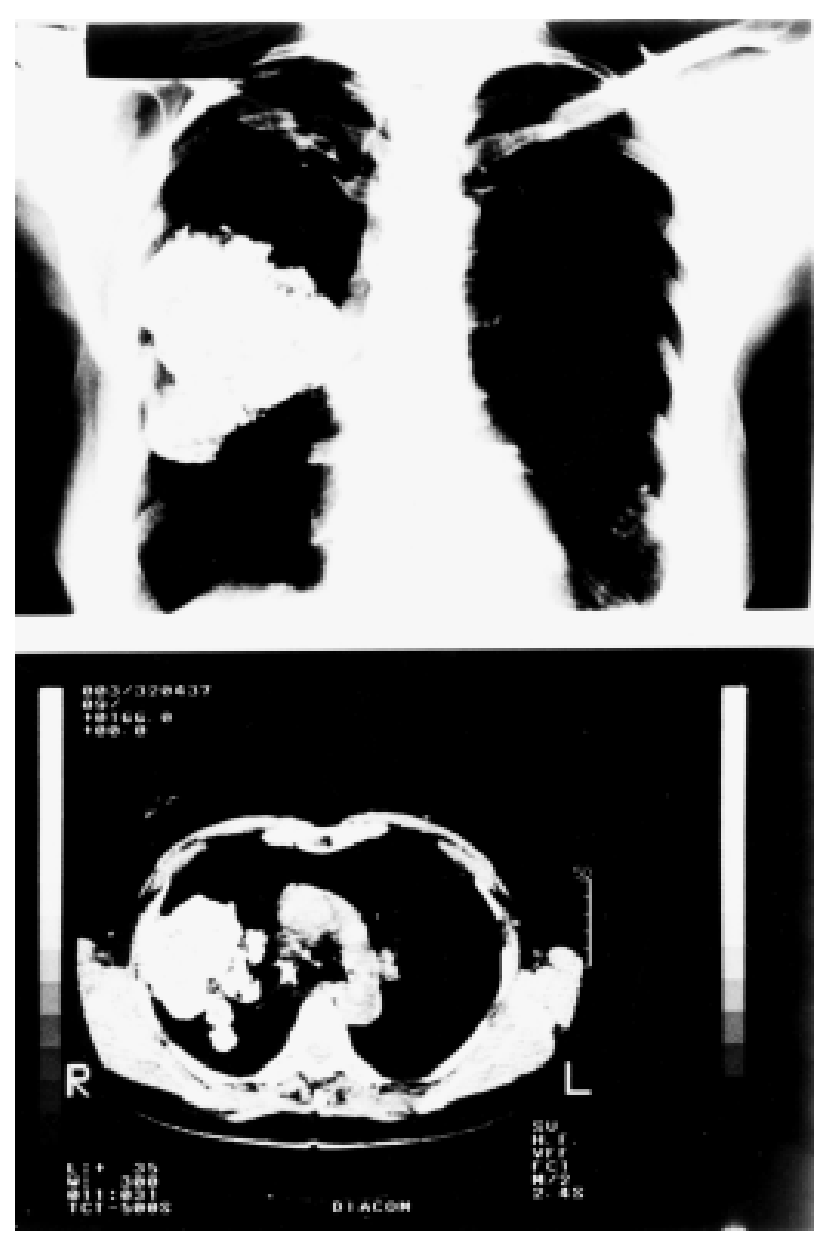

Figura $1-R X$ e $T C$ de tórax evidenciando massas condromatosas.

1. Patologista do Hospital Cardoso Fontes - Rio de Janeiro-RJ

2. Cirurgião do Hospital Cardoso Fontes - Rio de Janeiro-RJ

3. Endoscopista do Hospital Cardoso Fontes - Rio de Janeiro-RJ

Recebido em 25/07/2000

Aceito para publicação em 27/06/2001

Trabalho realizado no Hospital Cardoso Fontes — Rio de Janeiro-RJ. 
alteravam o estado clínico da paciente, que informou ter este diagnóstico estabelecido há mais de oito anos. Após estabilização hemodinâmica, foi submetida à laparotomia, quando se verificou a presença de múltiplos tumores endo e exofíticos, com aspecto de cachos, elevando a mucosa como "leiomiomas" e projetando-se além da serosa (Figura 2). Estas lesões se localizavam em corpo e antro gástrico, e uma, de grande volume, na junção esofagogástrica. $\mathrm{O}$ fundo do estômago e os demais segmentos intestinais estavam poupados. Realizou-se gastrectomia subtotal alargada ressecando-se toda a pequena curvatura (Pauchet) incluindo-se, na peça operatória, o tumor exofítico extramucoso justa-cárdia. A reconstituição do trânsito digestivo foi feita por gastrojejunostomia término-lateral, completada por êntero-êntero-anastomose laterolateral (Braun). Evolução pós-operatória sem intercorrências. A paciente encontra-se bem clinicamente após um ano de operada. No exame histopatológico da peça cirúrgica, foram utilizados métodos de coloração de rotina em hematoxilina-eosina e especiais em tricomia de Gomori e Van Giemson, tentando a identificação celular, que só ficou definida após estudos imuno-histoquímicos, realizados no Hospital Pedro Ernesto, que revelaram as seguintes características: tumor estromal, com positividade para proteína S.100, vimentina e CD34 e negativo para actina (antígeno para identificação de fibras musculares lisas), tratando-se assim de tumor gastrintestinal do nervo autonômico (GANT) denominado como plexossarcoma (Figura 3). Na revisão da literatura, juntando as duas patologias encontradas, condromatose pulmonar e plexossarcoma gástrico, caracterizam um caso de tríade de Carney em sua forma incompleta.

\section{DISCUSSÃO}

A tríade de Carney foi descrita em 1979 por JA Carney como uma síndrome neoplásica multicêntrica, que ocorre predominantemente em mulheres jovens ${ }^{1}$. Quatro anos mais tarde, o mesmo autor publicou trabalho com 24 casos, dos quais apenas seis pacientes apresentavam a tríade
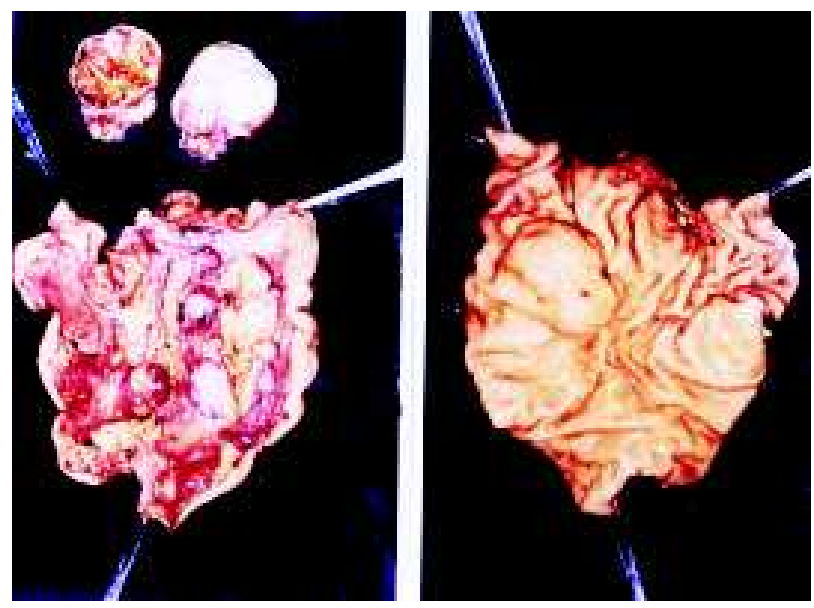

Figura 2 - Peça cirúrgica mostrando múltiplas tumorações com projeções endo e exofíticas.

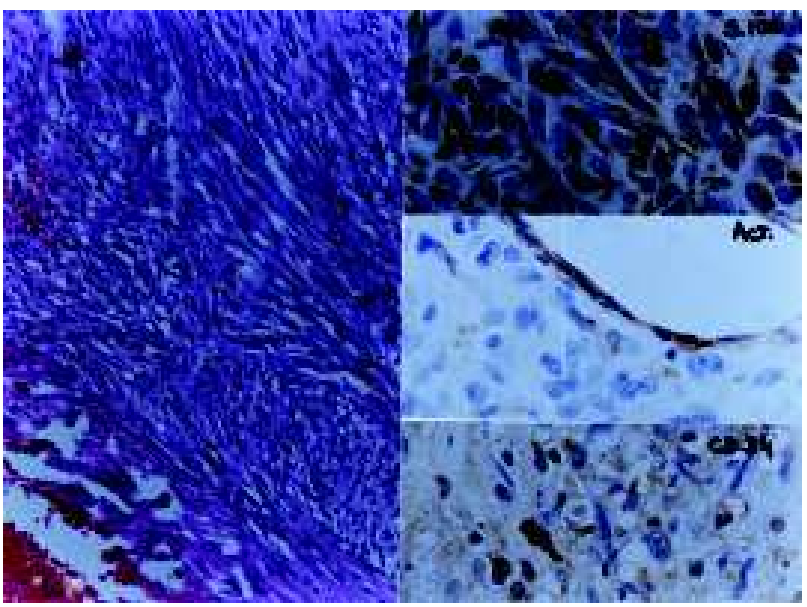

Figura 3 - Comprovação histopatológica de plexossarcoma HE à esquerda e IH à direita da foto.

completa ${ }^{2}$. Já em 1999, revisando a literatura mundial, estudou 79 pacientes sendo que $78 \%$ tinham a síndrome incompleta composta, na grande maioria dos casos, pela combinação de duas lesões : condroma pulmonar e tumores estromais gástricos. O intervalo médio entre o aparecimento da primeira e da segunda lesões foi de seis anos, sendo o mais longo de 26 anos. Neste trabalho, utiliza-se o novo conceito de tumor estromal do trato gastrintestinal ${ }^{3}$.

Tumores estromais são lesões relativamente comuns no trato gastrintestinal. Usualmente solitários, eram classificados como sendo, em grande maioria, de origem muscular lisa e denominados leiomiomas, tumores leiomiomatosos e leiomiossarcomas, ou seja, lesões benignas, borderlines ou malignas, na dependência de fatores como tamanho, necrose, invasão de tecidos vizinhos, e, critério definitivo para considerá-los malignos, contagem do número de mitoses por campo de grande aumento.

$\mathrm{O}$ advento da imuno-histoquímica trouxe, nos últimos cinco a dez anos, desenvolvimento significativo no conhecimento dessas lesões, conforme sua origem celular. Tumores gastrintestinais, até então classificados em sua maioria como de origem muscular, passam a chamar-se, de forma geral, de tumores estromais (GIST) e tomam denominações específicas quando se determina sua origem, surgindo então os tumores gastrintestinais do nervo autonômico (GANT), de origem no plexo mioentérico e chamados agora de plexossarcomas.

Cerca de $50 \%$ a $70 \%$ dos tumores estromais, sejam eles GIST ou GANT, desenvolvem-se no estômago em indivíduos acima de 50 anos. Seu tamanho pode variar, atingindo por vezes, até $20 \mathrm{~cm}$ de diâmetro. São bem circunscritos, lobulados, mas não encapsulados. Embora a lesão seja intramural, projeta-se para a luz do órgão, podendo ulcerar, e para a serosa, de modo endo e exofítico.

Pascal et al. ${ }^{4}$ os descrevem, chamando atenção para o fato de estes tumores fazerem parte da tríade de Carney, em pacientes mais velhos do que inicialmente descrito, ocorrendo em uma faixa etária próxima dos 58 anos de 
idade. A paciente em estudo, no momento do diagnóstico, tinha 53 anos.

Tumores gastrintestinais de origem neural lembram tumores musculares epitelióides (leiomiossarcoma epitelial) sendo o fenótipo neural definido em estudo imunohistoquímico, que mostra fibras positivas para proteína S100, CD34 e vimentina (antígenos de definição neuroectodérmica e fibroblástica), e negativas para actina (antígeno do músculo liso) ${ }^{5}$

Este conceito explica por que na tríade de Carney, inicialmente descrita, aparece a denominação de leiomiossarcomas epitelióides, e, posteriormente, em revisão de 1999, como no presente caso, já se encontra a nomenclatura de tumores estromais e plexossarcomas fazendo parte da mesma.

Plexossarcomas contêm elementos neuroaxonais e células de Schwann dispostos de maneira diferente dos schwanomas e neurofibromas. A maioria deles atinge grandes volumes (77\% têm mais de $5 \mathrm{~cm}$ em diâmetro e $45 \%$ mais de $10 \mathrm{~cm}$ ), e são múltiplos como os da paciente em sua apresentação.

Critérios para definir malignidade ainda não estão estabelecidos, mas existe um consenso de que o tamanho e índice mitótico, como nos demais tumores estromais, sejam os mais expressivos.

Carney, em 1999, afirma que, além da maioria destes pacientes apresentar a forma incompleta da tríade, a recorrência tumoral se faz a grandes intervalos de tempo e com metástases hepáticas. Aventa a possibilidade de ocorrência familiar.

No caso em questão, a associação de condromatose pulmonar e plexossarcoma nos leva a afirmar, assim como Yagihashi $\mathrm{S}$ et al. ${ }^{5}$, tratar-se da tríade de Carney na sua forma incompleta.

\begin{abstract}
The authors present a case of an incomplete form of Carney's Triad.They emphasize the use of immunohistochemistry to classify gastrointestinal stromal tumors and policy of long term follow-up.
\end{abstract}

Key Words: Gastric stromal sarcoma; Pulmonary chondroma; Carney triad.

\title{
REFERÊNCIAS
}

1. Carney JA. The triad of gastric epithelioid leiomyosarcoma, pulmonary chondroma, and functioning extraadrenal paraganglioma: a five-year review. Medicine (Baltimore), 1983, 62:3, 159-69.

2. Carney JA. The triad of gastric epithelioid leiomyosarcoma, functioning extra-adrenal paraganglioma, and pulmonary chondroma. Câncer, 1979; 43:(1): 374-82.

3. Carney JA. Gastric stromal sarcoma, pulmonary chondroma, and extra-adrenal paraganglioma(Carney Triad): natural history, adrenocortical component, and familial occurrence (see comments). Mayo Clin Proc, 1999, 74:6, 543-52.

4. Pascal RR et al. Neoplastic Diseases of the Small and Large Intestine In Silverberg SG, ed. Principles and Practice of Surgical Pathology and Cytopathology, $3^{\mathrm{a}}$ ed New York ,University of Maryland Medical System, 1997, (2) 1801 a 1866.
5. Yagihashi S et al. Gastric sub-mucosal tumours of neurogenic origin with neuroaxonal and schwann cell elements $\mathrm{J}$. Pathology 153:41-50-1987.

Endereço para correspondência:

Dra. M. ${ }^{\mathrm{a}}$ da Glória Patello de Moraes

Rua Santa Clara, 356/902

22041-010 - Rio de Janeiro - RJ 